\author{
Claude Guérin \\ Michael A. Matthay
}

\section{Acute cor pulmonale and the acute respiratory distress syndrome}

Received: 8 December 2015

Accepted: 17 December 2015

Published online: 13 January 2016

(C) Springer-Verlag Berlin Heidelberg and ESICM 2016

\section{Guérin $(\bowtie)$}

Service de Réanimation médicale, Hôpital de la Croix Rousse, Centre Hospitalier Universitaire (CHU) de Lyon, Université de Lyon, 103 Grande Rue de la Croix Rousse, 69004 Lyon, France e-mail: claude.guerin@chu-lyon.fr

\section{Guérin}

Equipe 13, Institut Mondor de Recherche Biomédicale, Créteil, France

\section{A. Matthay}

Departments of Medicine and Anesthesia, Cardiovascular Research Institute, University of California, San Francisco, USA

Acute respiratory distress syndrome (ARDS) is characterized by arterial hypoxemia secondary to protein-rich pulmonary edema associated with acute inflammation and loss of aerated lung volume [1,2]. ARDS also involves injury to the pulmonary circulation that is associated with pulmonary hypertension and an elevation in pulmonary dead space $[1,2]$. The pulmonary circulation is involved at different stages of ARDS with progression of the clinical syndrome. First, injury to the lung microcirculation causes an increase in lung vascular permeability which initiates the accumulation of pulmonary edema. Second, intravascular microthrombi can develop from an imbalance between procoagulant and fibrinolytic activity in the presence of acute inflammation and endothelial injury. Third, the marked reduction in functional residual capacity (FRC) can increase pulmonary vascular resistance (PVR). Fourth, positive pressure ventilation can induce high lung volume in some lung regions and compress alveolar vessels, resulting in increased PVR. The resulting higher regional FRC can also increase PVR. Fifth, hypoxic pulmonary vasoconstriction can further increase PVR. All these of mechanisms can contribute to an elevation in PVR that can occur within $48 \mathrm{~h}$ after the onset of ARDS, as demonstrated many years ago [3] and also more recently $[4,5]$. The elevation in PVR may also be exacerbated by hypercapnia and acidosis. These mechanisms are summarized in Fig. 1.

An elevation in PVR has long been recognized as a predictor of poor prognosis in ARDS. Under normal conditions, the right ventricle (RV) pumps against a low resistance pulmonary circulation, but in the presence of an acute increase in afterload from a rise in PVR, the RV attempts to compensate by increasing end-systolic and end-diastolic volumes. If the increase in afterload is substantial, impairment of RV systolic function and interventricular septal kinetics results in a reduction in cardiac output and acute core pulmonale (ACP) with RV failure and shock. Before the era of lung protective ventilation, the incidence of ACP from elevated PVR in ARDS was as high as $60 \%$ [6].

In a recent article in Intensive Care Medicine, Mekontso-Dessap and colleagues [7] report the results of a study of 752 moderate to severe ARDS patients (ratio of partial pressure arterial oxygen and fraction of inspired oxygen: $\mathrm{PaO}_{2} / \mathrm{FiO}_{2}<200 \mathrm{mmHg}$ ) designed (1) to determine the incidence of ACP, (2) to test a clinical score to predict the presence of ACP and (3) to determine the association of ACP with mortality. The diagnosis of ACP was determined by transesophageal echocardiography (TEE) and defined by septal dyskinesia with a dilated RV, end-diastolic RV/left ventricle area ratio of $>0.6$, and a score of $>1$ for severe ACP. Overall, ACP developed in 
Fig. 1 Several mechanisms contribute to an increase in pulmonary vascular resistance $(P V R)$ and pulmonary hypertension that may develop in the presence of moderate to severe acute respiratory distress syndrome $(A R D S)$, including microthrombi, hypoxemia, hypercapnea, pulmonary edema, regional overdistension of the lung [increase in functional residual capacity $(F R C)]$ and regional loss of lung volume (decrease in FRC)

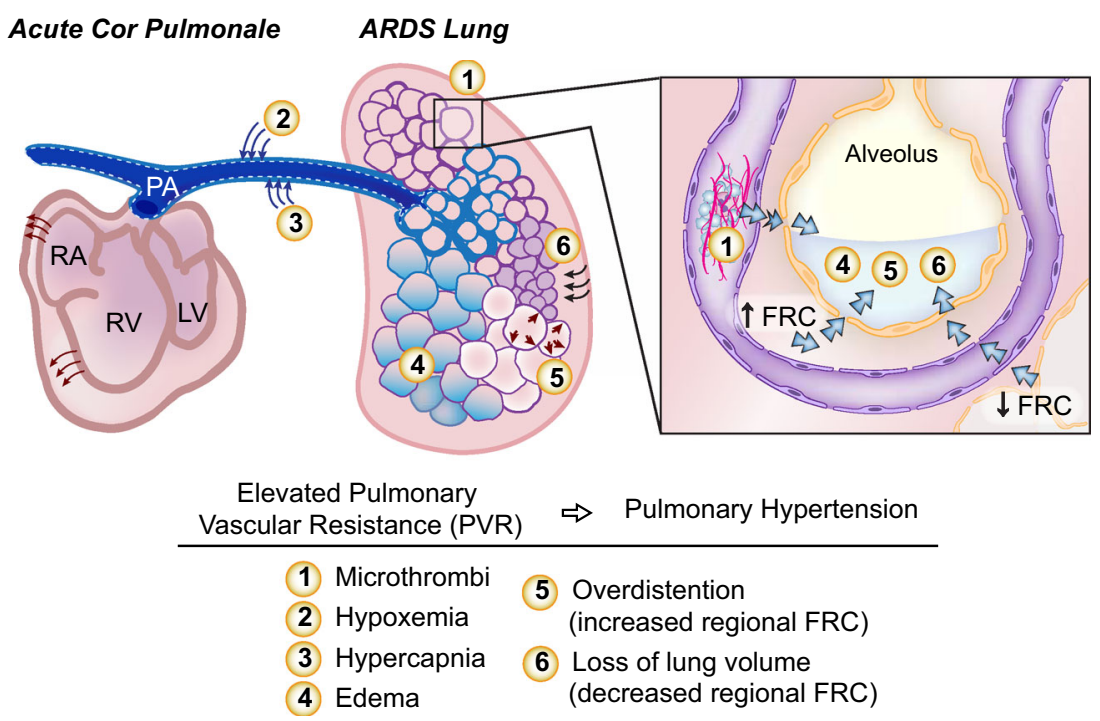

$22 \%$ of the patients. The investigators created and tested an ACP predictive clinical risk score. There were 502 patients assigned to the derivation cohort and 250 patients to the validation cohort. The four-point score (odds ratio of $>2$ ) has four components: (1) pneumonia as the cause of ARDS, (2) a driving pressure of $\geq 18 \mathrm{cmH}_{2} \mathrm{O}$, (3) a $\mathrm{PaO}_{2} / \mathrm{FIO}_{2}$ of $<100 \mathrm{mmHg}$ and (4) a partial pressure of carbon dioxide $\left(\mathrm{PaCO}_{2}\right)$ of $>48 \mathrm{mmHg}$. The score performed moderately well with reasonable discrimination and good calibration. The authors propose that clinicians can use this scoring system to determine if the ARDS patient should have TEE to diagnose ACP. The risk of ACP was 19,34 and $74 \%$ with scores of 2,3 , or 4 , respectively. Hospital mortality was only significantly higher in patients with severe ACP $(p<0.03)$, although there was a trend for higher mortality in patients with and without ACP (45 vs. $25 \% ; p<0.17$ ).

What can we learn from this study in the era of lung protective ventilation? First, although ACP is less common than in the past, a $22 \%$ incidence is still substantial in patients with moderate to severe ARDS. The proposed clinical score may assist physicians in their decisionmaking on whether or not to perform a TEE to diagnose ACP, although we favor using a score of 4 when the incidence would be approximately $75 \%$. If there were a more specific therapy to apply to patients with ACP, then a TEE would be indicated even if the predictive score were lower. Since TEE is invasive, most intensivists are not skilled in the use of TEE, and TEE is contraindicated in some patients, the incorporation of TEE into regular clinical practice is difficult. Alternatively, transthoracic echocardiography (TTE) is non-invasive and practical to use, but the specific criteria for diagnosing ACP cannot be achieved in most patients with TTE.

What should intensivists do to minimize the risk of developing ACP? First, it should be emphasized that the incidence of ACP has already be reduced through the use of lung protective ventilation in the clinical setting of lower tidal volumes and reduced plateau airway pressure. It is possible that minimizing end-inspiratory lung volume and recruiting the lung to maintain regional FRC via an adequate combination of tidal volume and positive endexpiratory pressure (PEEP) to promote a driving pressure of $<18 \mathrm{cmH}_{2} \mathrm{O}$ would result in a further reduction of ACP, but a prospective trial is needed to test this hypothesis. Inhaled nitric oxide, a selective pulmonary vasodilator, has been used to reduce PVR and improve oxygenation [8]. However, no benefit on mortality has been found in several trials [9], albeit these trials were completed before the current practice of lung protective ventilation for ARDS (low tidal volume [10], prone position [11], neuromuscular blockade [12]).

When clinicians are confronted with ACP, hemodynamic support with intravenous fluids and vaosopressors is needed. Treatment with norepinephrine or dobutamine can increase RV contractility. Enhancing preload with a fluid challenge can also be considered. One strategy is to assess the preload dependence of the cardiac output, which requires continuous monitoring (pulmonary artery catheter or the Picco device). If preload-dependence is present, fluid removal should be discontinued, and intravenous fluids should be administered. In the absence of preload dependence, fluids should be removed under the control of preload-dependence assessment. Other strategies include prone positioning and lowering of the PEEP, or further reduction of tidal volume associated with extracorporeal $\mathrm{CO}_{2}$ removal. Prone positioning may be useful because it allows a reduction in PEEP, thereby increasing oxygenation and FRC by promoting lung recruitment, as previously proposed [13]. However, these strategies for treating ACP have not yet been tested prospectively. 
In summary, the study by Mekontso-Dessap et al. [7] provides new information on the incidence of ACP $(22 \%)$ in moderate to severe ARDS in the era of lung protective ventilation. These authors report a significant association of severe ACP with higher mortality and propose a four-point clinical score that may have value for assessing the benefit (or not) of TEE to diagnose ACP in ARDS patients. More studies are needed to determine the efficacy of ventilator strategies (including prone positioning) and new pharmacologic agents to attenuate the incidence and severity of ACP in ARDS.
Acknowledgments The authors appreciate the assistance of Diana Lim in preparing the illustration.

\section{Compliance with ethical standards}

Conflicts of interest On behalf of all authors, the corresponding author states that there is no conflict of interest.

\section{References}

1. Nuckton TJ, Alonso JA, Kallet RH, Daniel BM, Pittet JF, Eisner MD, Matthay MA (2002) Pulmonary deadspace fraction as a risk factor for death in the acute respiratory distress syndrome. N Engl J Med 346:1281-1286

2. Price LC, McAuley DF, Marino PS, Finney SJ, Griffiths MJ, Wort SJ (2012) Pathophysiology of pulmonary hypertension in acute lung injury. Am J Physiol Lung Cell Mol Physiol 302:L803-L815

3. Zapol WM, Snider MT (1977) Pulmonary hypertension in severe acute respiratory failure. $\mathrm{N}$ Engl J Med 296:476-480

4. Bull TM, Clark B, McFann K, Moss M (2010) Pulmonary vascular dysfunction is associated with poor outcomes in patients with acute lung injury. Am J Respir Crit Care Med 182:1123-1128

5. Cepkova M, Kapur V, Ren X, Quinn T, Zhuo H, Foster E, Liu KD, Matthay MA (2007) Pulmonary dead space fraction and pulmonary artery systolic pressure as early predictors of clinical outcome in acute lung injury. Chest 132:836-842

6. Jardin F, Gueret P, Dubourg O, Farcot JC, Margairaz A, Bourdarias JP (1985) Right ventricular volumes by thermodilution in the adult respiratory distress syndrome. A comparative study using two-dimensional echocardiography as a reference method. Chest 88:34-39
7. Mekontso-Dessap A, Boissier F, Charron C, Begot E, Repessé X, Legras A, Brun-Buisson C, Vignon $\mathrm{P}$, Vieillard-Baron A (2016) Acute cor pulmonale during protective ventilation for acute respiratory distress syndrome: prevalence, predictors, and clinical impact. Intensive Care Med. doi: 10.1007/s00134-015-4141-2

8. Rossaint R, Falke KJ, Lopez F, Slama K, Pison U, Zapol WM (1993) Inhaled nitric oxide for the adult respiratory distress syndrome. N Engl J Med 328:399-405

9. Afshari A, Brok J, Møller AM, Wetterslev J (2010) Inhaled nitric oxide for acute respiratory xdistress syndrome (ARDS) and acute lung injury in children and adults. Cochrane Database Syst Rev 7:CD002787. doi: 10.1002/14651858.CD002787.pub2

10. The Acute Respiratory Distress Syndrome Network (2000) Ventilation with lower tidal volumes as compared with traditional tidal volumes for acute lung injury and the acute respiratory distress syndrome. N Engl J Med 342:1301-1308
11. Guerin C, Reignier J, Richard JC, Beuret P, Gacouin A, Boulain T, Mercier E, Badet M, Mercat A, Baudin O, Clavel M, Chatellier D, Jaber S, Rosselli S, Mancebo J, Sirodot M, Hilbert G, Bengler C, Richecoeur J, Gainnier M, Bayle F, Bourdin G, Leray V, Girard R, Baboi L, Ayzac L, Group PS (2013) Prone positioning in severe acute respiratory distress syndrome. N Engl J Med 368:2159-2168

12. Papazian L, Forel JM, Gacouin A, Penot-Ragon C, Perrin G, Loundou A, Jaber S, Arnal JM, Perez D, Seghboyan JM, Constantin JM, Courant P, Lefrant JY, Guerin C, Prat G, Morange S, Roch A, Investigators AS (2010)

Neuromuscular blockers in early acute respiratory distress syndrome. $\mathrm{N}$ Engl $\mathrm{J}$ Med 363:1107-1116

13. Vieillard-Baron A, Charron C, Caille V, Belliard G, Page B, Jardin F (2007) Prone positioning unloads the right ventricle in severe ARDS. Chest 132:1440-1446 